\title{
IBRD AND ITS INVOLVEMENT IN MODERNISING AND IMPROVING THE FUNCTIONALITY OF PENSION SYSTEMS
}

\author{
Cristina Roşu \\ “Vasile Alecsandri” University of Bacău, Romania \\ cristinaciuraru@yahoo.com
}

\begin{abstract}
In our research we review the International Bank for Reconstruction and Development's (IBRD) most important contributions to the functionality of the pension systems around the world. The pension systems design constitutes an important premise for the adequate functioning of these systems. In international practice, there is a wide variety of principles and mechanisms which can constitute the foundation of pension systems, the most common being materialized in the multi-pillar pension system, promoted by the IBRD. Its involvement in modernizing and improving the functionality of pension systems has reached also many other aspects such as evaluation of the national pension systems' performance, financial assistance to governments with the aim of meeting the objectives corresponding to pension systems, scientific, technical and informational support. We conclude that IBRD's involvement in modernizing and improving the functionality of pension systems has determined a significant transformation of the national pension systems, especially in Latin America and Eastern and Central Europe. However, its well-known multi-pillar model is not free of criticism as a result of the various analytical errors.
\end{abstract}

\section{Keywords}

IBRD; pension system; multi-pillar; pension performance indicators; pension system evaluation

\section{JEL Classification}

H55

\section{Introduction}

The current national context, which is characterized by the ageing of the population and the reduction of the contributors-beneficiaries (dependency) ratio has determined, at the level of international organisms and governments, a growing interest in issues concerning the organization and functioning of pension systems.

Since the beginning of the 1990s, these issues has been one of the priorities of the International Bank for Reconstruction and Development (IBRD - World Bank). Studies conducted for this purpose have shown the need for reform in most countries in the world.

In IBRD's view, the reformation of a public pension scheme of the type Pay As You Go (PAYG) can be carried out by means of one out of five alternatives, as follows (Holzman \& Hinz, 2005):

a) the support of parametric reforms that maintain the structure of the benefits, the public administration and the unfinanced nature of the scheme, which involves only changes in the corresponding parameters (raising the minimum required years of contributions, raising the retirement age and the contribution rates, the shift from benefits indexation depending on the accrual rate of medium wages to the indexation of benefits depending on the inflation rate etc.); the unfinanced scheme is characterised by the fact that the payable pensions are allocated on the basis of 
collected current contributions, while the existence of a surplus at a certain time represents an exceptional circumstance;

b) the implementation of notional accounts, which modify the structure of benefits (they function basically on the principle of defined contributions and depend on the life expectancy at the moment of retirement and on the "notional interest rate" (which is regularly equal to the rate of economic growth) applied to the sums "collected" in individual accounts), but which maintains the type of administration and the nature of the financing.

c) the adoption of private management and "Fully Funded" schemes (based on defined benefits or defined contributions), which limit the involvement of public administration only to the achievement of the objective related to the reduction and elimination of poverty among the elderly;

d) the introduction, within the public pension system, of a prefinancing component (which can be partial or total) of benefits, based either on the principle of defined benefits or on that of defined contributions; for the purpose of making the system more efficient, the management of investments can be externalised to the private sector;

e) the diversification of the nature of benefits, administration and funding by choosing the multi-pillar model.

The choice of one of the alternatives mentioned above depends on the necessities and the specific situation in each country, but also on the inherited system and the existing possibilities for reform. IBRD's preference for the last alternative was based on the need for diversity and for the sharing of the responsibility concerning the incomes corresponding to the retirement period at the level of more actors.

\section{IBRD's view regarding the organisation and functioning of national pension systems}

In this context, in one of its early forms, the multi-pillar system proposed by the international forum in an intensely-covered report entitled "Averting the Old Age Crisis: Policies to Protect the Old and Promote Growth” was formed of (IBRD, 1995):

- the first pillar, organised and administered publicly, which involved mandatory subscription and which was aimed primarily at the reduction and prevention of poverty among pensioners;

- the second pillar, administered at a private level, is mandatory for the contributors to the first pillar;

- the third pillar, also administered privately, and which involves voluntary subscription.

In IBRD's view, by means of these three pillars three major functions of a pension system can be fulfilled, as follows: redistribution, saving and insurance. Redistribution involves financial transfers from one group of people to another with the aim of preventing poverty, saving leads to lifelong consumption smoothing, whereas insurance protects individuals against negative events such as an economic recession, bad investment, inflation, etc.

The first pillar satisfies the need of redistribution, the second and the third cover the savings component and together they manage to protect the beneficiaries against the afore-mentioned risks.

Under the circumstances of implementing the multi-pillar model, the responsibility of governments regarding pension systems targets three important aspects: imposition, normalization and stimulation.

Considering that, in general, not all individuals save voluntarily for their retirement, a certain degree of coercion is inevitable. However, it must be correlated with the elaboration of relevant and intelligible norms, which are meant to uphold the 
credibility of the pension system (public and private). Moreover, the normalization process cannot disregard those aspects which stimulate the call for retirement savings, such as: offering relative or absolute guarantees concerning the amount of the future pension, the deductibility of the pension contributions, the creation of respectable institutions that supervise the administration of the pension schemes in favour of the participants, etc.

In IBRD's vision, the first pillar of the multi-pillar system proposed initially was designed to have a more reduced dimension and, at the same time, to be of a pay-asyou-go type in order to avoid the problems specific to provident funds (financed funds) administered at a public level (unsatisfactory results obtained from investments in government bonds, high contributions or reduced benefits, etc.) and which exist in certain states from the African and Asian continents (Zambia, Malaysia, Singapore). The administrative and fiscal capacity of the state, as well as its intention to redistribute through the pension system lay at the basis of selecting one of the modalities for providing benefits in case of pillar I (presented in figure 1).

Pillar II was considered to be a solution, on the one hand, for avoiding some of the political and economic difficulties to which the public pension scheme was exposed and, on the other hand, for increasing the accumulation of capital, the development of the financial market, etc.

The third pillar was devised in order to satisfy the wishes for a higher income and supplementary protection during the retirement period.

In the case of pillars II and III, IBRD's recommendation targeted primarily the individual pension plans, especially due to their advantages, such as: wide coverage at the levels of the individuals, portability ${ }^{1}$, work mobility, etc. However, their implementation required the existence of well-grounded and rigorously normalised banking and capital markets and of a wide range of financial instruments that could satisfy the pension funds' investment needs.

Synoptically, the multi-pillar system (in its initial form) proposed by IBRD is represented in figure 1.
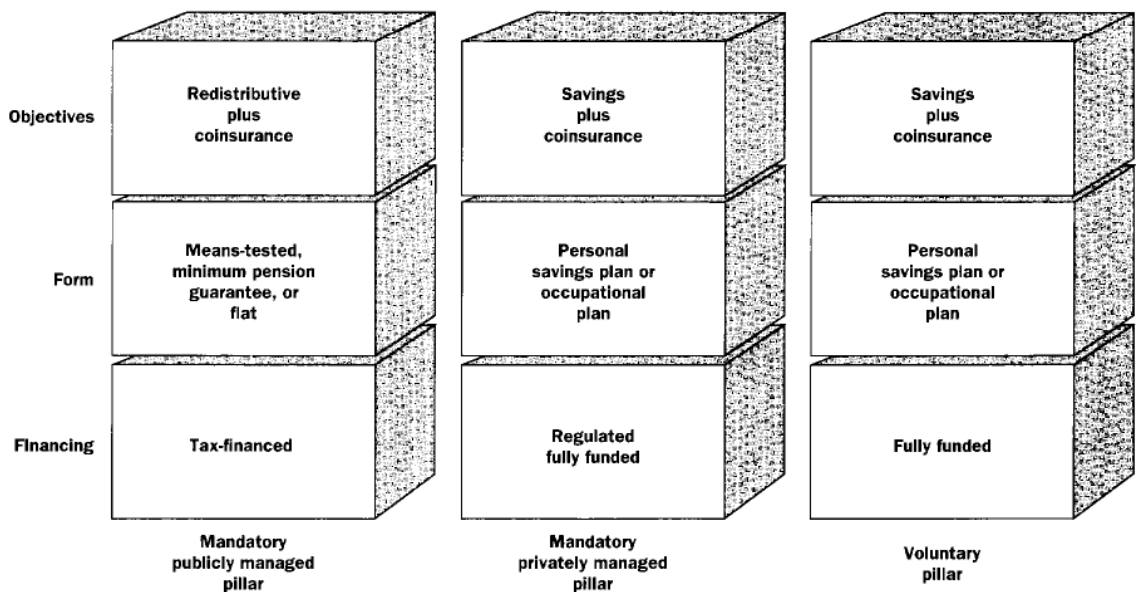

Figure 1 The multi-pillar system (initial form) promoted by the International Bank for Reconstruction and Development

Source: World Bank (1994), Averting the Old Age Crisis: Policies to Protect the Old and Promote Groth, Oxford University Press, p. 15

\footnotetext{
${ }^{1}$ The portability of pension rights is equivalent to the possibility of retaining their value as a result of switching workplaces or the country of residence.
} 
Taking into consideration the modalities for providing benefits in the case of Pillar I, we observe the lack of earnings-related benefits. Concerning this subject, in IBRD's standpoint, the obligation to give benefits to those with high incomes in direct proportion to these incomes, on the one hand, and the redistribution to those with low incomes, on the other, can lead to excessive contributory quotas and to substantial transfers to wealthy individuals (the so-called perverse redistribution).

When the multi-pillar was launched, its adoption was positively seen by IBRD as a source of economic development and a generator of citizens' wellbeing (be they young or old), in effect for a long time, as a result of the functions it accomplishes, namely, redistribution, saving and insurance.

\section{New perspectives on national pension systems}

More than ten years after the publication of the report that left an important mark on the evolution of pension systems in more states, the World Bank reaffirmed and updated its position, as a result of the accumulated experience and research, in another report entitled "Old-Age Income Support in the 21st Century: An International Perspective on Pension Systems and Reform". In this study, the need of reforming pension systems is highlighted, as a result of the unfavourable evolution of national pension systems, from the perspective of their sustainability and that of the distortions they provoke at the level of an economy.

The updating of the multi-pillar system, supported by IBRD starting with 1994, consisted in its redefinition and expansion to five essential categories, as shown in table 1.

Table 1 Taxonomy of the new multi-pillar pension system supported by the World Bank

\begin{tabular}{|c|c|c|c|c|c|c|}
\hline \multirow[b]{2}{*}{ Pillar } & \multicolumn{3}{|c|}{ Target groups } & \multicolumn{3}{|l|}{ Main criteria } \\
\hline & $\begin{array}{l}\text { Lifetime } \\
\text { poor }\end{array}$ & $\begin{array}{l}\text { Informal } \\
\text { sector }\end{array}$ & $\begin{array}{c}\text { Formal } \\
\text { sector }\end{array}$ & Characteristics & Participation & $\begin{array}{l}\text { Funding or } \\
\text { collateral }\end{array}$ \\
\hline 0 & $X$ & $X$ & $x$ & $\begin{array}{l}\text { "Basic" or "social pension," at least social assistance } \\
\text { (universal or means tested) }\end{array}$ & $\begin{array}{l}\text { Universal } \\
\text { or residual }\end{array}$ & $\begin{array}{l}\text { Budget or } \\
\text { general revenues }\end{array}$ \\
\hline 1 & & & $X$ & $\begin{array}{l}\text { Public pension plan, publicly managed (defined } \\
\text { benefit or notional defined contribution) }\end{array}$ & Mandated & $\begin{array}{l}\text { Contributions, } \\
\text { perhaps with some } \\
\text { financial reserves }\end{array}$ \\
\hline 2 & & & $X$ & $\begin{array}{l}\text { Occupational or personal pension plans (fully } \\
\text { funded defined benefit or fully funded defined } \\
\text { contribution) }\end{array}$ & Mandated & Financial assets \\
\hline 3 & $x$ & $X$ & $X$ & $\begin{array}{l}\text { Occupational or personal pension plans (partially } \\
\text { or fully funded defined benefit or funded defined } \\
\text { contribution) }\end{array}$ & Voluntary & Financial assets \\
\hline 4 & $X$ & $X$ & $X$ & $\begin{array}{l}\text { Access to informal support (family), other formal } \\
\text { social programs (health care), and other individual } \\
\text { financial and nonfinancial assets (homeownership) }\end{array}$ & Voluntary & $\begin{array}{l}\text { Financial and } \\
\text { nonfinancial assets }\end{array}$ \\
\hline
\end{tabular}

Note: The size and appearance of $\mathrm{x}$ reflect the importance of each pillar for each target group in the following increasing order of importance: $\mathrm{x}, \mathrm{X}, \mathrm{X}$. Source: Holzman, R., Hinz, R. (2005), Old-age Income Support in the 21st Century: An International Perspective on Pension Systems and Reform, The World Bank, p. 82

Through the promotion of the new multi-pillar model, IBRD addresses more firmly the imperative needs of the states, such as those related to the reduction of poverty and the coverage not only of employees from the formal sector, but also of those from the informal one. With the aim of raising the pension systems' coverage, certain states like the USA, Germany, Japan, or New Zealand, have implemented, at the level of public or private pension systems, a mechanism by means of which the state or the 
employer contributes, on behalf of the employee, to the pension fund, in direct proportion to his contribution (Matching Defined Contribution) (Holzman, 2012).

According to IBRD, a system that incorporates more pillars than the 5 pillars mentioned in table 1 may provide, through its diversity and flexibility, adequate and affordable pensions, thus being able to fulfil the most important functions of pension systems, as follows: the reduction of poverty levels among the retired citizens, protection in case of economic, political or demographic risks, which are inherent to pension systems, as well as the accumulation of savings for old age.

However, for the conception of a pension system every state needs to take into consideration its own economic, social, political, financial, institutional conditions, etc., in order to ensure the viability of the system. Thus, the multi-pillar model can take various forms and practical modes of implementation; yet, a few elements are essential to the nature of the implemented model (Holzman \& Hinz, 2005):

- elements that correspond to the zero pillar, which should cover pensioners whose incomes from the contributory period were too low, or who worked in the formal sector only on a temporary basis; the viability of these elements depends on the existence of other vulnerable groups and on the availability of budgetary resources;

- elements that allow the prefinancing of future pensions, which can be adopted by any of the pillars and which have certain advantages, both from an economic perspective (they can lead to increasing savings at the national level), as well as from a political one (the presence of resources which are necessary for funding the future pension rights can produce high levels of credibility among the population).

Besides the requirement that these essential elements should be respected, the reform of the pension system must have as objectives (Holzman \& Hinz, 2005):

- providing adequate pensions, which should be sufficient for preventing poverty and for ensuring, for the majority of retired persons, a level of consumption that is comparable to the one before the retirement occurred;

- providing pensions that are possible given the financial power of the contributors and of the society, and which are not detrimental to other economic and social objectives;

- ensuring the long-term sustainability of the system;

- implementing a robust system that is capable to resist the major political or demographic shocks or economic volatility, etc.

Backgrounded on these objectives, IBRD formulated a series of "performance" indicators that can assist the measurement of a pension system's capacity to deliver, in a safe and efficient manner, the benefits promised to present and future generations, such as (Pallares-Miralles et al, 2012):

- the coverage degree of the pension system;

- the adequacy of the provided benefits;

- the financial sustainability of the pension system and the degree of providing for pensions from the collected contributions;

- economic efficiency, namely, the minimization of the distortions that the pension system can cause at the level of the labour market, individual savings, etc.;

- administrative efficiency, which lies in the minimization of the costs that correspond to the collection of contributions, the payment of benefits and, respectively, the management of investments;

- the robustness of benefits when they are exposed to certain risks and uncertainties.

For the evaluation of national pension systems IBRD employs, besides the indicators mentioned above, a series of indicators that are meant to diagnose the environment in which a certain pension system operates, such as: the fertility rate, the elderly dependency ratio, the workforce participation rate, life expectancy, etc., as well as 
indicators describing the architecture/design of a pension system, as well as the rules at its foundation (contribution quota, eligibility criteria).

The analysis of these indicators facilitates the carrying out of statistical reports and comparisons between states, as well as the identification of good practice in the domain with the purpose of future use in different national contexts. Still, as the international organism itself admits, the creation of an informational basis at an international level regarding the policy in the area of pensions is still difficult (Pallares-Miralles et al, 2012).

Therefore, besides the manner in which national pension systems are organised, IBRD is also preoccupied with their functionality, giving assistance to governments with the aim of meeting the objectives corresponding to pension systems, precisely in the case of those that target their sustainability, the coverage degree and the adequacy of benefit. To this end, the international body makes use of instruments for microstimulation or actuarial prediction such as Axia Apex Model of Pension Entitlements (APEX) or Pension Reform Options Simulation Toolkit (PROST) (Dorfman \& Palacios, 2012).

The numerous conferences organised in the domain of pension systems, the various collaborations with other international institutions (such as the Organisation for Economic Cooperation and Development, the Inter-American Development Bank, the International Monetary Fund, etc.) that tackle problems regarding pension systems in the entire world, as well as the richness of the conducted research, including studies and analyses carried out in each member state, have facilitated the accumulation of a rich and valuable collection of knowledge on the basis of which IBRD can be rightly named "the bank of accumulated and, most of all, valorized knowledge".

Besides the technical and informational support provided, IBRD has also backed up financially certain states, with a view to adopting the new proposed system, but taking into account the fact that there is a close link between the implementing capacity of each member state and the degree to which the reformation is possible, namely, the activation of all the pillars or only of some of them. For instance, not every state is ready for the introduction of a private pillar and, as a consequence, it should not even do that unless it fulfils a series of minimal conditions (Holzman \& Hinz, 2005):

- the existence of a powerful nucleus of banks and other 'healthy' financial institutions, which are capable of offering credible services for the management and administration of the funds' assets;

- the long-term governmental commitment for the promotion of sound macroeconomic policies, which would contribute to the creation of new jobs and the increase of revenues;

- the creation of a pertinent, stable and intelligible regulatory environment.

\section{Conclusions}

The multi-pillar model should have remained only a reference framework, as IBRD itself admits, thus allowing states to adjust the structure of their pension systems to the specific national context. However, through the years, the multi-pillar system has proved to be a model that is worth following. Thus, many states, especially some from Latin America and Central and Eastern Europe have reformed their national pension systems taking into account the measures or guidelines proposed by IBRD. Nevertheless, this did not lead to the desired outcomes, a fact which favoured the emergence of criticism concerning IBRD, as a result of the various analytical errors identified in the case of the multi-pillar model, such as (Barr \& Diamond, 2009):

- the lack of vision concerning the effects that all the pillars might have on a certain economy, beyond the effects of one pillar only; 
- the disregard of certain problems that may occur at an individual level, related to the necessity of pertinent and objective information in order to take the decisions that can influence their standard of living during the retirement period;

- the laying of emphasis on the manner of financing pensions (PAYG or accumulation of assets) and not on the source of providing the real consumption, respectively the GNP/GDP (gross national/domestic product) and the manner of distributing it the levels of the retired generation and the active one;

Additionally, many of the advantages of the multi-pillar model, especially of the mandatory private pension pillar (lack of political interference, resistance to demographic changes, the development of the financial market, the facilitation of economic growth, increasing the rate of employment, the diversification of risks, etc.) have been demystified throughout the years, as a result of their failure to fulfil expectations or because the same effects (be they positive or negative) can be obtained even in the context of a public pension system alone (thus making the creation of a mandatory private pension pillar ineffectual) (Bar, 2001; Stiglitz \& Orszag, 2001; Barr \& Diamond, 2009).

In a report that evaluates the assistance offered by IBRD for the implementation of the different multi-pillar pension systems, besides the recognition of certain aspects that have not met their target, such as the persistence of political influence on the private pension schemes, the failure to achieve objectives related to increasing the level of savings, the development of the capital market and the increasing of coverage among the persons from the informal sector, the failure to diversify portfolios (most of the investments taking the form of government bonds), emphasis is laid on the fact that many of the initial conditions (administrative capacity, macroeconomic stability, etc.), which are necessary for the adoption of such a reform, have not been fulfilled satisfactorily, whereas other requirements (the amount of the debt, the corruption level, etc.) have been subsequently neglected (Independent Evaluation Group - World Bank, 2006). The fact that the World Bank has upheld the implementation of the multi-pillar model even under these circumstances reveals either the distortion of the reality by the factors involved in reforming national pension systems (according to certain interests they may have) or the existence of excessive toleration levels shown by the international organism.

\section{References}

Bar, N. (2001), The welfare State as Piggy Bank. Information, Risk, Uncertainty and the Role of the State, Oxford University Press.

Barr, N., Diamond, P. (2009), Reforming Pensions: Principles, Analytical Errors and Policy Directions, International Social Security Review, 62(2), 5-29.

Dorfman, M., Palacios, R. (2012), World Bank Support for Pensions and Social Security, Social Protection and Labor Discussion Paper, 1208, The World Bank.

Holzman, R. (2012), Global Pension Systems and Their Reform. Worldwide Drivers, Trends and Challenges, Social Protection and Labor Discussion Paper, 1213, The World Bank.

Holzman, R., Hinz, R. (2005), Old-age Income Support in the 21st Century: an International Perspective on Pension Systems and Reform, The International Bank for Reconstruction/The World Bank.

Independent Evaluation Group - World Bank (2006), Pension Reform and the Development of Pension Systems. An Evaluation of World Bank Assistance, The World Bank, Washington, D.C. 
Pallares-Miralles, M., Romero, C., Whitehouse, E. (2012), International Patterns of Pension Provision II. A Worldwide Overview of Facts and Figures, Social Protection and Labor Discussion Paper, 1211, The World Bank.

Stiglitz, E. J., Orszag, R. P. (2001), Rethinking Pension Reform: 10 Myths about Social Security Systems, in New Ideas About Old Age Security: Toward Sustainable Pension Systems in the 21st Century, Edited by Holzmann, R. et al, The International Bank for Reconstruction and Development / The World Bank, 17-56.

The International Bank for Reconstructions and Development/The World Bank (1994), Averting the Old Age Crisis: Policies to Protect the Old and Promote Groth, Oxford University Press. 